\title{
A rare case of bilateral lens dislocations
}

\author{
Fionn Coughlan, ${ }^{1}$ Kitty Shakur, ${ }^{2}$ Pav Gounder ${ }^{2}$
}

${ }^{1}$ Department of Ophthalmology, Royal Perth Hospital, Perth, Western Australia, Australia ${ }^{2}$ Department of Ophthalmology, Royal Perth Hospital, Perth, Western Australia, Australia

Correspondence to Dr Fionn Coughlan, fionn3@gmail.com

Accepted 17 May 2017
CrossMark

To cite: Coughlan $\mathrm{F}$ Shakur K, Gounder P. BMJ Case Rep Published Online First: [please include Day Month Year]. doi:10.1136/ bcr-2017-220848

\section{DESCRIPTION}

A 39-year-old man presented to our hospital following transfer from a rural site with an acute right eye anterior lens dislocation following a traumatic blow to the head. He had been hit 7 days prior and had suffered gradual vision loss in the right eye since then. Visual acuity was counting fingers at $1 \mathrm{~m}$ in his right eye and perception of light in his left eye. He had an intraocular pressure (IOP) of $50 \mathrm{~mm} \mathrm{Hg}$ in his right eye on arrival. He had a CT head non-contrast performed. The axial (figure 1) and sagittal (figures 2 and 3) slices demonstrated a right eye anterior lens dislocation and a left eye posterior lens dislocation. The left eye had been injured 3 years prior and the patient had not sought treatment for it at the time. On examination, the left eye was found to have a chronic retinal detachment and a posterior lens dislocation. His right eye had been his only seeing eye and now had poor vision due to the acute injury. The anterior lens dislocation in his right eye was visible on slit lamp examination (figure 4). Intravenous acetazolamide was given to lower the IOP and a lensectomy performed that night. The patient returned to theatre 3 days later for a vitrectomy and insertion of an anterior chamber lens. The CT (figure 1) shows the bilateral lens dislocation very clearly and highlights the need for accurate clinical details and history to avoid confusion when assessing acute pathology in a case with bilateral findings. Trauma

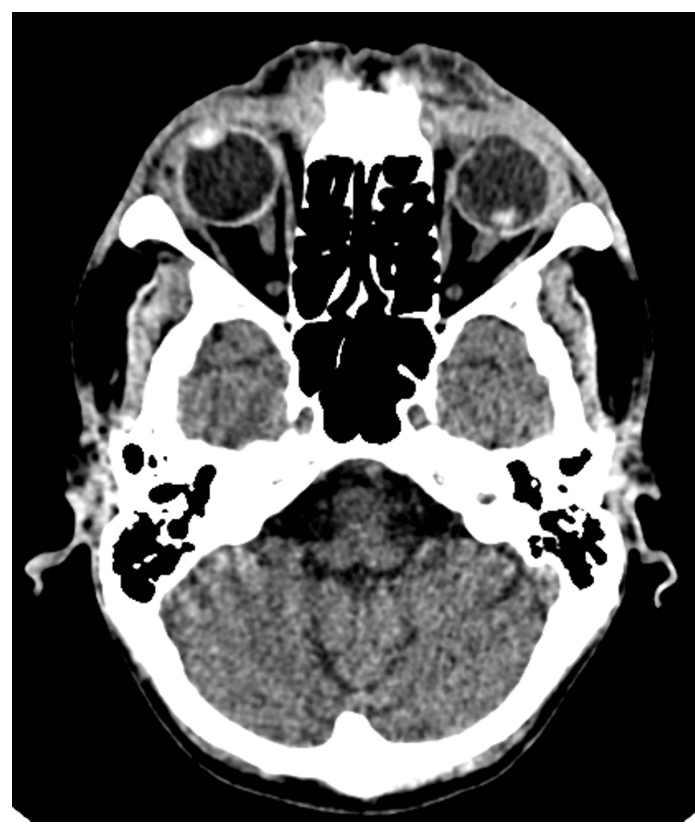

Figure 1 Axial CT head non-contrast showing anterior lens dislocation in the right eye and posterior lens dislocation in the left eye.

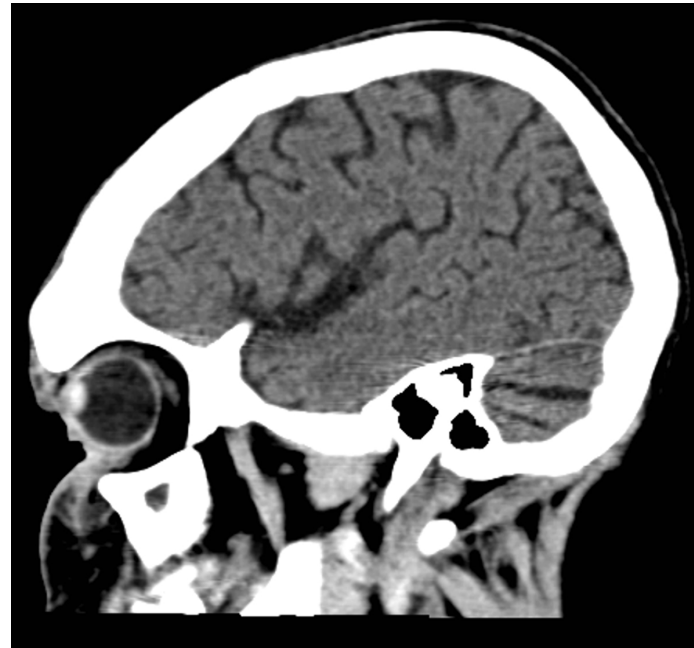

Figure 2 Sagittal CT head non-contrast showing anterior lens dislocation in the right eye.

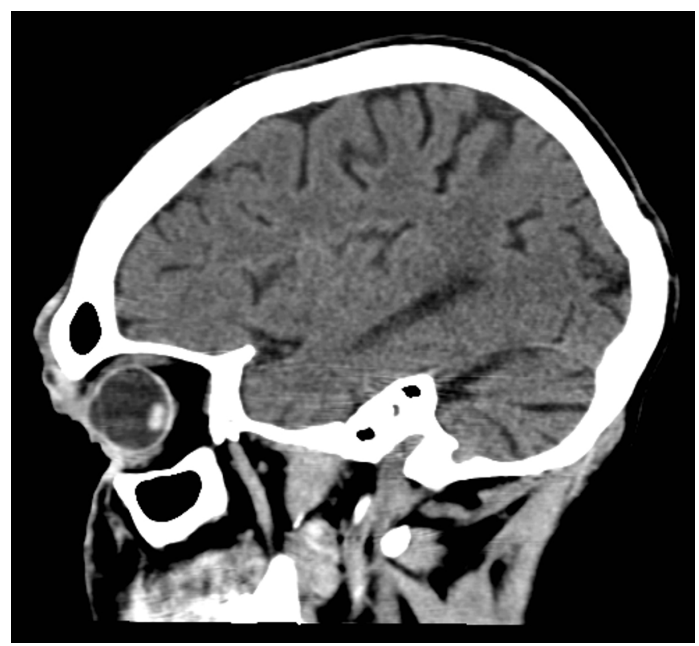

Figure 3 Sagittal CT head non-contrast showing posterior lens dislocation in the left eye.

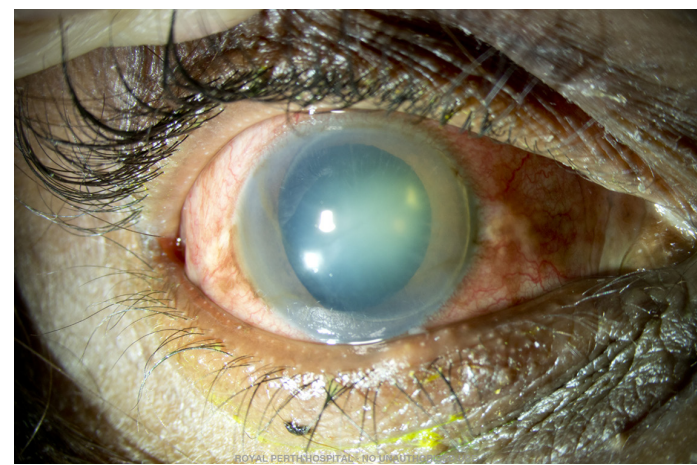

Figure 4 Clinical photograph from slit lamp examination showing right eye anterior lens dislocation. 


\section{Learning points}

- An accurate clinical history is required, in particular when bilateral pathologies exist. Correct clinical information is important when making imaging requests to guide reporting.

- Lens dislocation should be considered in cases where visual acuity is reduced in the setting of ocular or facial trauma. ${ }^{1}$

- Anterior lens dislocations are an ophthalmological emergency and prompt treatment should be initiated. ${ }^{3}$

is the most common cause of lens dislocation or subluxation; however, lens dislocation is a rare complication of head injury. ${ }^{12}$ Anterior lens dislocations are an ophthalmological emergency as they can lead to acute angle closure glaucoma and their prompt recognition and treatment are essential. ${ }^{3}$
Contributors FC: involved in all phases of editing and drafting of the article. KS: initial patient examination, assisting with patient consent and with article content. PG: editing of final draft and image selection.

Competing interests None declared.

Patient consent Obtained.

Provenance and peer review Not commissioned; externally peer reviewed.

(C) BMJ Publishing Group Ltd (unless otherwise stated in the text of the article) 2017. All rights reserved. No commercial use is permitted unless otherwise expressly granted.

\section{REFERENCES}

1 Jarrett WH II. Dislocation of the Lens. A study of 166 hospitalized cases. Arch Ophthalmol 1967;78:289-96 http://jamanetwork.com/journals/jamaophthalmology/ fullarticle/628905

2 Lee S, Hayward A. Bellamkonda VR traumatic lens dislocation. International Journal of Emergency Medicine 2015;8:16 https://www.ncbi.nlm.nih.gov/pmc/articles/ PMC4456605/

3. Coughlan F, Shakur K, Wong E. (Apr 12). Incidental finding of right lens dislocation following trauma. \{Online\}. 2017 http://www.eurorad.org/case.php?id=14655.

Copyright 2017 BMJ Publishing Group. All rights reserved. For permission to reuse any of this content visit

http://group.bmj.com/group/rights-licensing/permissions.

BMJ Case Report Fellows may re-use this article for personal use and teaching without any further permission.

Become a Fellow of BMJ Case Reports today and you can:

- Submit as many cases as you like

- Enjoy fast sympathetic peer review and rapid publication of accepted articles

- Access all the published articles

Re-use any of the published material for personal use and teaching without further permission

For information on Institutional Fellowships contact consortiasales@bmjgroup.com

Visit casereports.bmj.com for more articles like this and to become a Fellow 